lan C. Bickle, MB BCh BAO, FRCR

Department of Radiology

RIPAS Hospital,

Bandar Seri Begawan

Brunei
Correspondence: Dr. lan C. Bickle Department of Radiology RIPAS Hospital

Bandar Seri Begawan BA1710

Brunei Darrusalam

Phone: (673) 8612182

Fax: (673) 2242690

Email: ian@bickle.co.uk

Reprints will not be available from the author.

The author declared that this represents original material that is not being considered for publication or has not been published or accepted for publication elsewhere, in full or in part, in print or electronic media; that the manuscript has been read and approved by the author, that the requirements for authorship have been met by the author, and that the author believes that the manuscript represents honest work.

Disclosures: The author signed a disclosure that there are no financial or other (including personal) relationships, intellectual passion, political or religious beliefs, and institutional affiliations that might lead to a conflict of interest.

\section{Nasopharyngeal Carcinoma Presenting as a Dual Territory Stroke: The Hyperdense Artery Sign}

This 63-year-old Chinese female with both diabetes and hypertension underwent $\mathrm{CT}$ imaging of the brain after presenting with a progressive left sided hemiplegia.

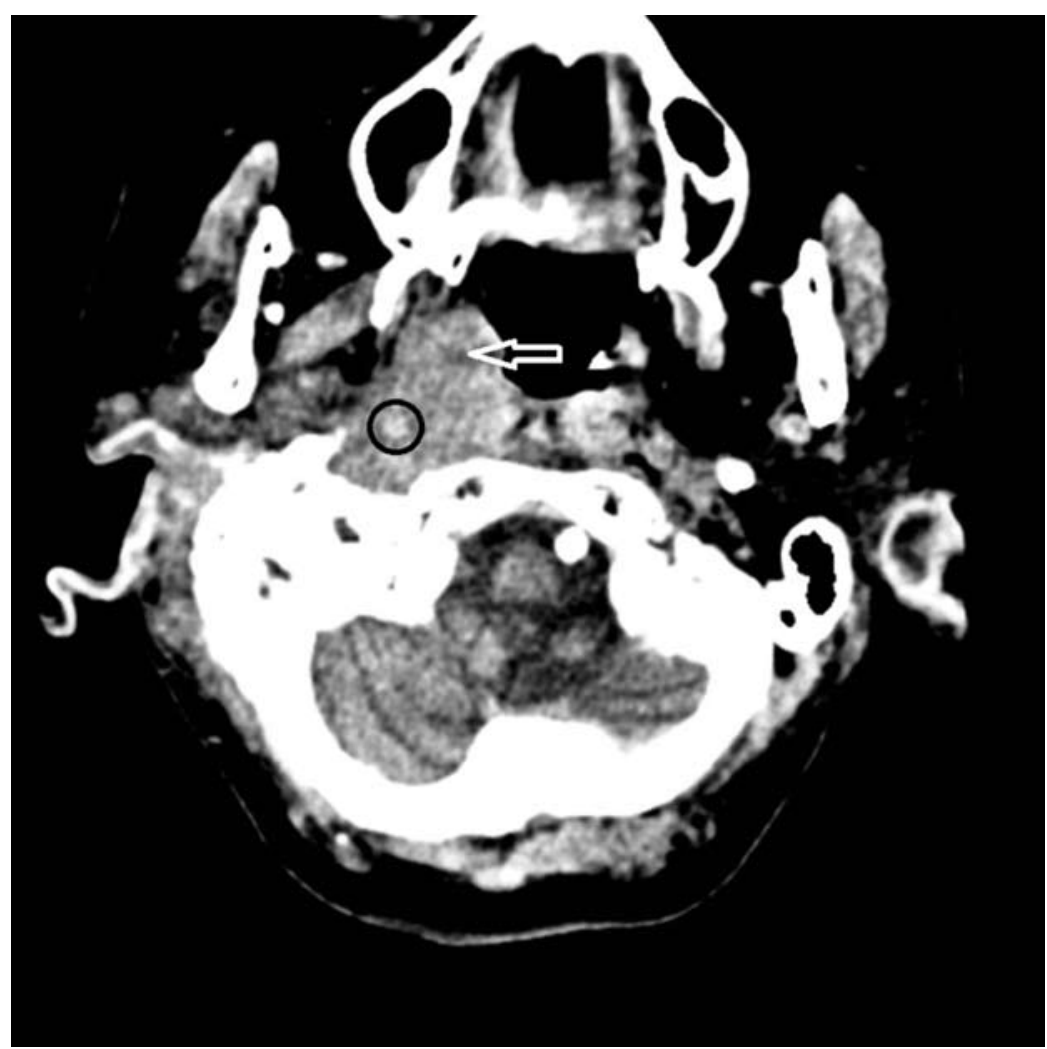

Figure 1a. Axial Unenhanced CT of the Brain: Thrombosis in the right internal carotid artery (black circle) with surrounding tumour in the nasopharyngeal recess (white arrow). 
The 'hyperdense artery sign' is a generic description that can be evident in any artery of the body on unenhanced CT occurring due to the presence of intraluminal thrombosis (Figure 1). It is a well-established sign most commonly described in CT imaging of the brain where it is visualised in the vast majority of cases in the middle cerebral artery in the context of an acute cerebral infarction.' It occurs uncommonly elsewhere with the internal carotid artery (ICA) and basilar artery being other clinically significant sites. The 'hyperdense ICA' sign has been reported to be a reliable and highly specific marker of thromboembolic occlusion of the internal carotid artery. ${ }^{2}$ The 'hyperdense artery sign' is related to the attenuation value of intraluminal thrombus. The CT attenuation value (Hounsfield unit or HU) of normal blood is dependent on the haematocrit ranging from 20 to $30 \mathrm{HU}$. As the process of thrombus retraction occurs, its water content decreases increasing the concentration of haemoglobin within the clot. As a result, this raises the attenuation value of the thrombus to $50-80 \mathrm{H}$. So the term 'hyperdense' is given. ${ }^{3}$

In this case, it proved to be the presenting symptom for an undiagnosed nasopharyngeal tumour, the thrombus likely developing as a complication of the surrounding tumour within the nasopharyngeal recess. The resultant outcome was a dual territory cerebral infarction of the anterior and middle cerebral artery territories both supplied by branches of the internal carotid artery (Figures $2 a$ \& 2b).
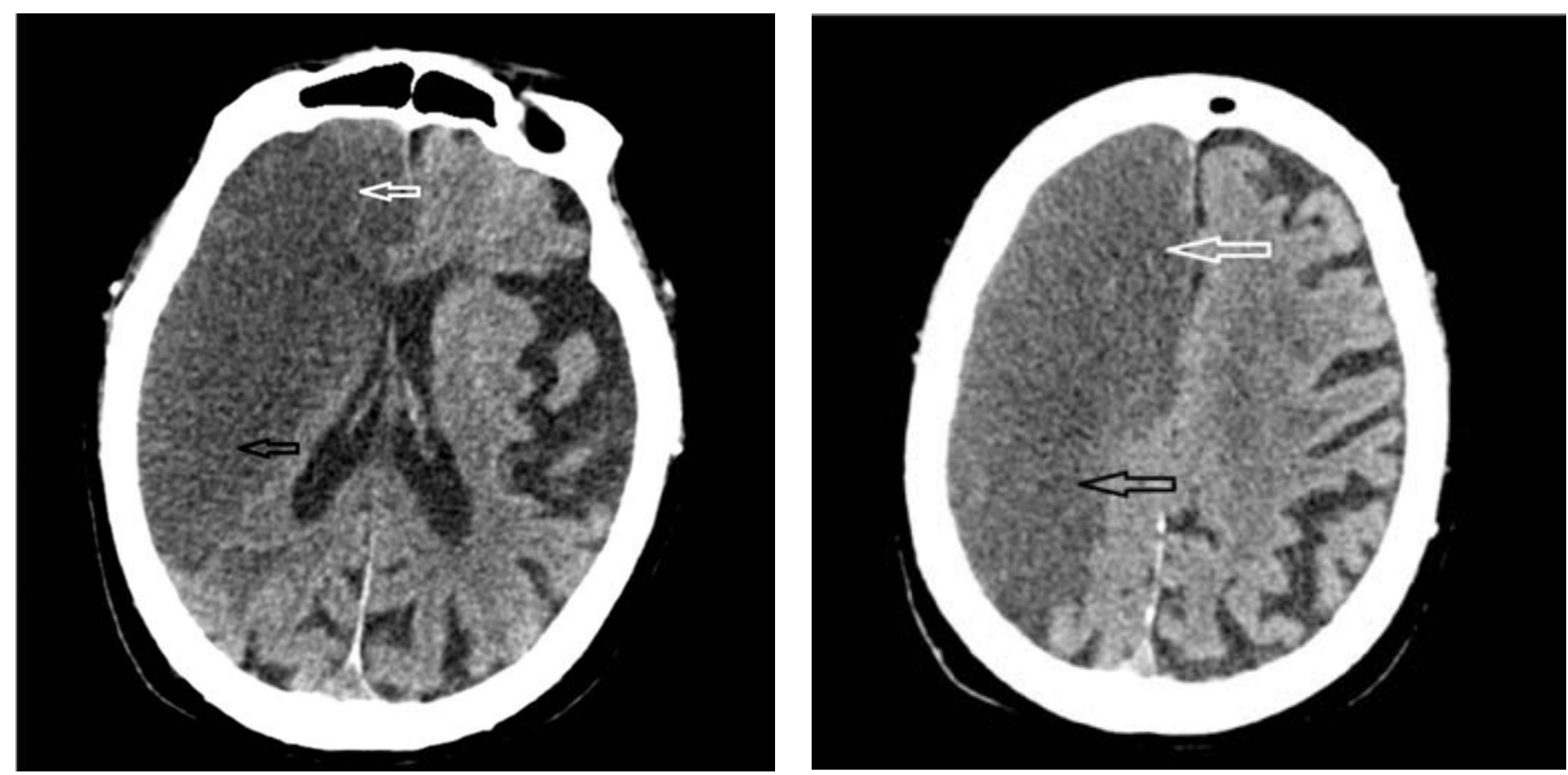

Figures 2a \& b. Axial Unenhanced CT of the Brain: Anterior cerebral artery territory (white arrow) and middle cerebral artery (black arrow) infarctions.

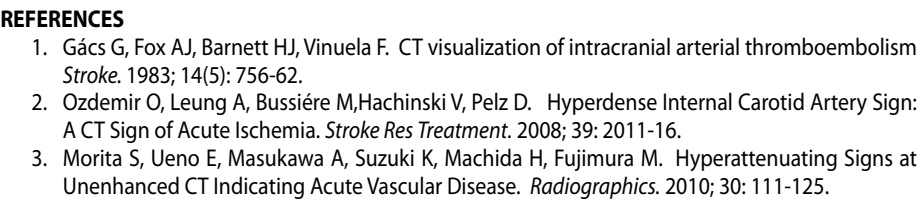

1. Gács G, Fox AJ, Barnett HJ, Vinuela F. CT visualization of intracranial arterial thromboembolism Stroke. 1983; 14(5): 756-62.

2. Ozdemir O, Leung A, Bussiére M,Hachinski V, Pelz D. Hyperdense Internal Carotid Artery Sign: A CT Sign of Acute Ischemia. Stroke Res Treatment. 2008; 39: 2011-16.

3. Morita S, Ueno E, Masukawa A, Suzuki K, Machida H, Fujimura M. Hyperattenuating Signs at Unenhanced CT Indicating Acute Vascular Disease. Radiographics. 2010; 30: 111-125. 